\title{
Challenges in Realising Sustainable Community Development in Rural South Africa
}

\author{
Bernice B. Van Schalkwyk \\ School for Geo and Spatial Sciences, North West University, Potchefstroom, South Africa
}

Email address:

bernicevanschalkwyk@yahoo.com

To cite this article:

Bernice B. Van Schalkwyk. Challenges in Realising Sustainable Community Development in Rural South Africa. Agriculture, Forestry and Fisheries. Special Issue: Planning for Sustainable Communities: Green-Spaces in Rural Areas. Vol. 4, No. 4-1, 2015, pp. 73-79.

doi: $10.11648 /$ j.aff.s. 2015040401.19

\begin{abstract}
The importance of rural development has long since been known but it has specific relevance to South Africa, where the poor quality of life is driving rural resident to migrate toward urban areas. This is turn is causing worrying problems for cities and towns which have to provide housing and services to the increased influx of new residents. The only solution to the rural exodus is to redevelop rural areas into sustainable communities. Having a clear definition and understanding of sustainable development and sustainable communities is a prerequisite in developing sustainable rural communities. To this end the Venn diagram of sustainability as it applies to communities is utilized, to incorporate social, environmental and economic issues into sustainable community planning and development. From this a better understanding of the interactions between the various spheres of sustainability can be had, leading to a better understanding of sustainable community development as a whole. Unfortunately there are several challenges in achieving sustainable rural communities. While most of these challenges are well known there are a few that are unique to the South African rural sphere. If development plans and policies aren't tailor made to adapt to these specific challenges then sustainable community development will never be possible in rural South Africa.
\end{abstract}

Keywords: Sustainable Development, Community Development, Rural Development

\section{Introduction}

Tostensen, Tvendten and Vaa [1] argue that while Africa is one of the least urbanized regions in the world it is also the region where towns and cities grow the fastest. By $200157 \%$ of the South African population was urbanized [2] and this percentage has risen during the last decade with the United Nations [3] estimating that $67.9 \%$ of the South African population will be living in cities by 2025 . This results in urban areas experiencing a shortage of employment and housing, increasing poverty, severe environmental problems and a lack of services, while rural areas are left drained.

One of the reasons for this drastic urbanization rate is the fact that rural areas are prone to chronic poverty. Large backlogs for services only add to the problem. Steps have to be taken to ensure that rural areas are developed to be lively and sustainable places where people can live and prosper.

In Africa countries migration to the city exceeds the capacity of these cities to accommodate their new residents. Van Buren, Van Bohemen, Itard and Visscher [4] state that "cities do not fulfill the promise of a better life that made people leave their rural villages". It is due to these factors that the concept of sustainable rural community development is of particular relevance to South Africa. Sustainable rural community development is necessary in order to achieve more integrated and sustainable rural areas with a better environment and a higher quality of life. Only once rural areas offer a lively, secure and sustainable living environment will the mass exodus to urban areas be halted.

\section{What is a Sustainable Community}

\subsection{Understanding Sustainable Communities}

Eliot [5] states that sustainable development refers plainly to maintaining development overtime. By this definition a sustainable community can be seen as a community in which development is maintained over time. Since development takes place in an economically geographic space with different impacts and outcomes there are certain preconditions for development that have to be met in order to mitigate the spatial impact of development. In their book Rogers, Jalal and Boyd [6] list nine ways in which to achieve sustainability. 
These methods include approaches such as letting "the markets take care of it". While these are all very useful insights they are simply not focused enough to address sustainability at community level.

Portney [7] reasons that the idea of sustainable communities grew out of the understanding that individual human behaviour, and the local governance context in which it takes place is of vital importance. Since the term community has come to mean many different things to many different people the idea of sustainable communities itself has come to mean many different things. Portney [7] states that "a sustainable community can be anything from a small neighbourhood, to a group of people who share some interests, to a program operated by a governmental or nongovernmental organization, to a rather localized ecosystem, to a multistate region encompassing numerous ecosystems". In the case of this study a sustainable community is seen as a geographically bounded area in which the residents meet their diverse needs while making effective use of natural resources, enhancing the environment, achieving social cohesion and strengthening their economic prosperity in such a manner that the needs of future generations will be met.

The ideal sustainable community can be defined along five typical dimensions as shown in Table 1. All five of these dimensions articulate with the three spheres of sustainability: society, environment, economy.

Table 1. Five dimensions of sustainable community development.

\begin{tabular}{ll}
\hline Dimension & Description \\
\hline Increased local economic diversity & $\begin{array}{l}\text { Economic development strategies should place an emphasis on increasing the local economic diversity. } \\
\text { This includes the development of local markets and local productions. Products that were previously imported } \\
\text { self-reliance }\end{array}$ \\
$\begin{array}{l}\text { seduced energy consumption and } \\
\text { management and recycling of waste. }\end{array}$ & $\begin{array}{l}\text { Ideally the use of energy and materials would be in balance with the earth's ability to absorb waste. The recycling of } \\
\text { waste can also be used as an economic gain if managed correctly. }\end{array}$ \\
$\begin{array}{l}\text { Protection of biodiversity and careful } \\
\text { stewardship of natural resources. }\end{array}$ & $\begin{array}{l}\text { careful stewardship of natural resources can also aid in the reduction of energy consumption and management of } \\
\text { waste. }\end{array}$ \\
A sustainable community is a community that provides for the housing and living needs of all its residents without \\
any prejudice. There isn't any class and race-based spatial separation of households or neighborhoods and everyone \\
\end{tabular}

Portney [7] further states that the concept of sustainable communities put the old adage of "think globally act locally" into practice. While sustainability represents a global goal, sustainable community development speaks to a local level. The task of planning for sustainable communities thus lies with the local authority. Agenda 21 [8] advocates the role of the local authority in the support of sustainable development by stating that: "Because so many of the problems and solutions being addressed by Agenda 21 have their roots in local activities, the participation and cooperation of local authorities will be a determining factor in fulfilling its objective. Local authorities construct, operate and maintain economic, social, and environmental infrastructure, oversee planning processes, establish local environmental policies and regulations, and assist in implementing national and subnational environmental policies. As the level of governance closest to the people, they play a vital role in educating, mobilizing, and responding to the public to promote sustainable development."

\subsection{Understanding the Venn Diagram of Sustainability as It Applies to Communities}

The Venn diagram of sustainability aids with the incorporation of social, environmental and economic issues into sustainable community planning and development. Rogers et al [6] posits that sustainability and sustainable development is comprised of three dimensions and that these dimensions are used to gauge the success of a relevant program or project. While each component should be given equal attention there are also areas where these components overlap. These areas are not often discussed in the literature regarding sustainable development despite the fact that they have the potential to significantly contribute to sustainable community development.

\subsubsection{Economy and Environment}

Ravets [9] asks the question that if economic activity has traditionally exploited natural resources how can there be a sustainable economy? In 1988 Collard, Pearce and Ulph [10] already identified that sustainable development requires the setting of constraints to the harvesting of resources at levels no higher than they can be regenerated naturally, and the waste disposal rates should not exceed that which can be managed by the ecosystem. This view strongly links the economic component of sustainability with the environmental and still rings true today. In the same vein as Collard et al, Ravetz [10] defines an environmentally sustainable economy as "activity and trading systems which co-exist with local and global capacities and limits". Bridger and Luloff [11] define environmentally sustainable economic development as local economic change contributing to environmental sustainability, while enhancing the local natural and constructed environment.

Roseland [12] recognizes that poverty is a major source of environmental degradation. Families collect firewood because they cannot afford other sources of heating, leading to deforestation in developing countries. Addressing the economic sphere of sustainability will also contribute towards the environmental sphere in a positive way.

Development often leads to resource depletion which in turn leads to the stagnation of development since natural resources are the building blocks for development. Rogers et 
al [6] argue that to minimize the consequences development has on the environment, and also on society, governments and decision makers should undertake a strategic assessment of policies and plans.

\subsubsection{Society and Environment}

According to Mohan and Lutz [13] sustainable development requires "an approach that will permit continuing improvements in the quality of life at lower intensity of resource use, thereby leaving behind for future generations an undiminished or even enhanced stock of natural resources". In 2008 Rogers et al [6] estimated the earth's carrying capacity, at US standards, to be about 1 billion people even though the population stood at nearly 6.3 billion by then. The complex question that then needs to be asked is what can be done about this?

Rogers et al [6] illustrates that poverty can lead to resource depletion and natural degradation in perpetuity. The poor pollute and erode the environment out of necessity, often leading to worse poverty. Several studies done at local level [6] indicate that poor communities are willing to invest in their environment under certain favorable conditions, such as when they have ownership and control over the property. This is an example of how a principle that seems directed solely at the social aspect of sustainability (housing and tenure) can also contribute to another component. Goodland and Daly [14] state that "although environmental sustainability is needed and originated because of social concerns, environmental sustainability itself seeks to improve human welfare and social sustainability by protecting the sources of raw materials used for human needs and ensuring that the sinks for human wastes are not exceeded".

\subsubsection{Economy and Society}

Rogers et al [6] posits that sustainable economic development is directly concerned with the increase in the standards of living of the poor. Ravetz [9] echoes this statement by stating that a socially sustainable economy deals with the "provision and equitable distribution of income, goods, services, security and employment". In $200520 \%$ of the world's richest people owned $82.7 \%$ of the world's wealth, with only $1.4 \%$ of wealth being attributed to the bottom $20 \%$ [15].

Rogers et al [6] rightly states that economic objectives should not be maximized without satisfying environmental and social constraints". The World Bank [16] mentions that over the past two decades the economic and social goals of sustainability have been shown to be highly compatible and complimentary to each other. Poverty reduction is driven by economic growth and an improved social outcome is good for growth. This however is not the case with the economic and environmental spheres of sustainability.

\subsection{Differences Between Urban and Rural Sustainable Communities}

Dalal-Clayton et al [17] states that the concepts of rural planning often vary and that this leads to confusion between planners, policy-makers and implementers. This can be seen in the case of South Africa where, until 1995, rural was defined as households not living in formally declared towns. Many of these areas defined as rural were actually urban areas without services. In the new democratic era in South Africa rural is now defined as "the sparsely populated areas in which people farm or depend in natural resources, including villages and small towns that are dispersed through these areas" [18]. This is not necessarily an astute definition as many households fall into both rural and urban categories as they derive their incomes from an assortment of sources. Gallent, Juntti, Kidd and Saw [19] advise defining a rural area based on an analysis of land-use mix, settlement structure and the way of life of its inhabitants. A rural area is seen as an area dominated by farming and forestry, made up of small, low order settlements and having a cohesive identity that is liked to an extensive landscape.

Gallent et al [19]define a sustainable rural community as:

- Having a flourishing local economy that is able to provide employment and contribute to wealth creation;

- Having engagement and participation by the residents;

- Having a sense of identity and belonging;

- Being a safe and happy place where residents have access to open recreational spaces;

- Providing basic amenities, community services and community facilities;

- Having good public transport systems which aid in connecting the community with a larger network of services, employment and other opportunities;

- Possessing adaptable spaces that can be used for different purposes;

- Provide a variation in housing and tenure types; and

- Being connected to the wider local, regional and national community.

Most developing countries have sought to use rural planning as a development tool and a method of poverty alleviation. The objectives of rural planning have evolved over time from a focus on increased production to concerns about equity, poverty alleviation and vulnerability reduction. Dalal-Clayton et al [17] states that "rural planning is concerned with planning for development, land use, the allocation and management of resources, including the rural-urban interface". Elliot [5] is of the opinion that the differences between urban and rural areas need to be understood so that effective approaches to sustainability can be developed.

\section{The Need and Importance of Planning for Sustainable Communities}

The Rural Development Framework (RDF) [18] defines rural areas as: "The sparsely populated areas in which people farm or depend on natural resources, including the villages and small towns that are dispersed through these areas. In addition, they include the large settlements in the former homelands, created by the apartheid removals, which depend 
for their survival on migratory labor and remittances. "

The According to the South African Government [20] South Africa is characterized by poverty, which is especially prevalent in rural areas, with around $70 \%$ of rural residents living in poverty. Rural economies are not sufficiently vibrant to provide the people with jobs and the cost of living is especially high. In the Integrated Sustainable Rural Development Strategy (ISRDS) [20] it is stated that the demographic of rural areas reflect past policies and that the legacy of the former homelands is "one of planned and deliberate poverty". Figure 1[22] illustrates the disparities between the number of rural and urban poor in Sub-Saharan Africa.

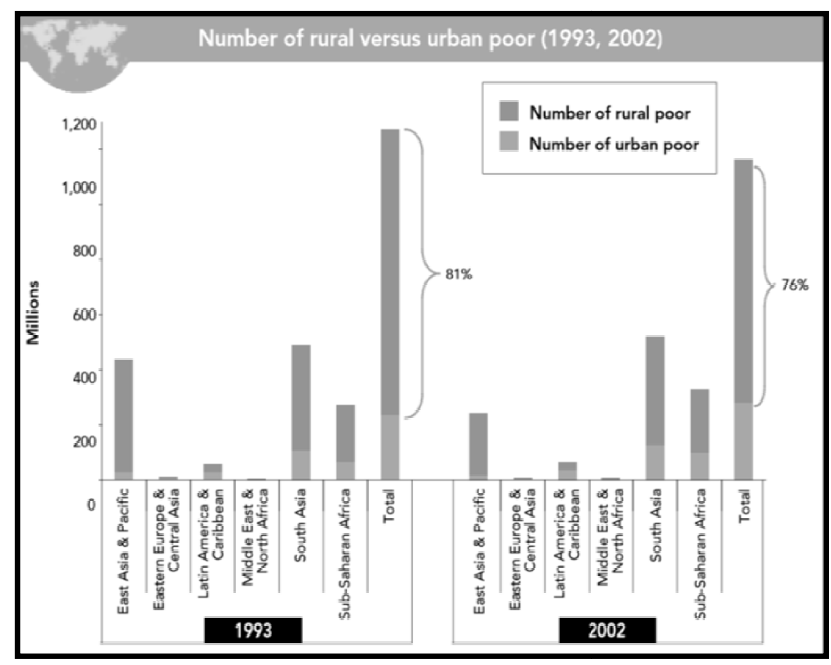

Figure 1. Number of rural versus urban poor.

Sustainable rural community development is essential for eradicating poverty (a Millennium Development Goal) since global poverty is overwhelmingly rural [21]. According to the United Nations [22] the number of poor people in rural areas far outweighs those in urban areas and that poverty is still more prevalent in rural areas. Therefor policies promoting agricultural and rural development are going to play a crucial role in reducing poverty in these regions. Portney [7] argues that sustainable communities can act as mechanisms with which to redress the negative and deleterious environmental and social impacts of economic development.

It can be argued that the term rural development used to comprise of state-led policies and programs to shape the rural landscape to meet the urban need [23]. It is therefore critical to coordinate rural development initiatives that will contribute to sustainable livelihoods for rural residents, taking into consideration the remoteness and potentials in rural areas [21].

Most often rural development refers only to the economic aspects of development with little attention given to social and environmental factors. The World Bank [24] defined rural development as a strategy designed to improve the economic and social life of the rural poor. Gangopadhyay, Mukhopadhyay \& Singh [25] states that "rural development aims at improving rural people's livelihoods in an equitable and sustainable manner, both socially and environmentally, through better access to assets, and services, and control over productive capital that enable them to improve their livelihoods on a sustainable and equitable basis". The United Nations [21] advocates for sustainable rural development stating that it is vital to the economic, environmental and social viability of nations.

The RDF [18] states that development in rural areas requires:

- Institutional development to help rural people set the priorities in their own communities and access funds to plan and implement local economic development.

- Investment in basic infrastructure and social services.

- Improvement in income and employment opportunities and a broadened access to natural resources.

- Establishment of periodic markets to restore basic economic rights to marginalized rural areas.

- Conservation of resources.

- Increased justice, equity and security.

\section{Challenges in Developing Sustainable Communities}

Apart from factors such as poverty, homelessness and environmental issues, bad administration and inadequate community initiatives are also responsible for the current issues threatening the development of sustainable communities. During the analysis and review of a template for integrated community sustainability planning in Canada [26] a few common challenges in sustainable community development was identified. These challenges are also applicable to the South African situation and are thus pertinent to this research. These challenges include integration, scale, governance, community inclusion and western concepts and methods of development.

\subsection{Integration}

Human settlements are often areas of inequality, segregation and exclusion. Despite government's best efforts the housing and service interventions for the poor have continued to perpetuate the apartheid urban form and legacy. The result has been the development of large dormitory settlements of low-cost houses on the urban periphery far from economic opportunities and rural areas being continually overlooked. The consequence is that people get trapped in poverty and are subject to long-term social costs. The perpetuation of the apartheid spatial form is a serious issue and the challenge articulated in 1994 continues.

The South African Cities Network [27] says that in an attempt to address the on-going challenge of integration of the apartheid urban form, municipalities have placed an increased importance on "integrated human settlements". Their efforts are focused on facilitating denser, better located, mixed-income, environmentally sustainable government-assisted housing. Despite this there is still considerable work to be done in developing policies and strategies to be implemented on a meaningful scale while the policy instruments and frameworks that are required for a 
coherent and implementable approach to integration are still undeveloped and require attention.

\subsection{Scale}

Projects for sustainable community development often involve individual initiatives that are geographically bounded. This means that they rarely influence municipal systems as a whole resulting in these projects often lacking the capacity to link the municipal planning decisions to the wider landscape [26].

Another challenge regarding scale is that the scale that is planned for is often too large. Bridger and Luloff [11] argue that national or global scale strategies often prevent meaningful and resolute action. It is further stated [11] that "at such macro levels, the scale of change required is so great that problems of coordination across political units are bound to be enormous". It is helpful to plan in terms of neighborhoods and ensuring that the scale of planning is driven by the pedestrian [28]. Community development projects are often planned on a larger scale that does not take walking distance and neighborhood boundaries into consideration. Campbell [29] says that it is also believed that the inhabitants of small-scale regions will be more aware of the causes and effects of their environmental actions than residents of larger communities.

According to Monto, Ganesh and Varghese [30] the problems in a settlement's living environment (poverty, shelter, sanitation, etc.) can be addressed at four different levels: national, city, neighborhoods, and household/shelter/workplace. These levels are useful in addressing sustainability issues and to develop targeted strategies as each level has its own unique issues and obstacles.

Policies developed at national level impact upon all other levels of human settlements. These policies have to be directly aimed at promoting sustainable community development in order to be effective. Actions focused on a local level can lead to quicker, visible changes and improvements.

\subsection{Governance}

Government structures often do not embrace sustainable development as a guiding planning principle resulting in the implementations of sustainability objectives often becoming difficult and resulting in ineffectiveness. Even the government sectors that have embraced the principles of sustainable community development have had considerable difficulty in translating strategies into practice.

Local government rarely incorporates a sustainability ethos into their planning until forced to. Ling et al [26] argues that "rather than merely planning for sustainability, as seems common, governments should be planning sustainably". Local government also often lacks the capacity to implement sustainability initiatives effectively. Building capacity at all levels of government as well as promoting good governance practices within and between spheres of government is crucial.

Political corruption acts as a big deterrent in realizing sustainable communities because the misappropriation of funds results in reduced effectiveness of community development initiatives.

\subsection{Community Inclusion}

Community engagement is crucial to assuring sustainable community development. Education and training should be given to the community to educate them on their options leading to an increase in public awareness. Government should provide and share information at all stages of development. A community should also be empowered to identify what they see as sustainability and these viewpoints should be included in the decision making process.

Inclusion also means planning for the bigger picture and defining long term goals, rather than a plan that reflects a short term agenda with poor attention to pluralism.

\subsection{Western Concepts and Methods of Development}

Binns \& Nel [31] state that the march of human progress has become a retreat for approximately one-sixth of mankind. After decades of steady economic advancement many countries have been thrown back into poverty. Binns \& Nel [31] further argue that "this meant the effective collapse of social services and infrastructure in many parts of Africa, coupled with hyperinflation, vast debt burdens and the disastrous effects of global trade". Many foreign aid as well as local programs has tried to lift communities out of this pit of despair, yet most have been futile. Successive generations of imported, Western development projects and strategies have failed to deliver meaningful reductions in poverty and to achieve the provision for basic needs. This led to the questioning of Western development concepts and methodologies.

The needs of communities in developing countries aren't the same as those faced by communities in the First world. African communities in particular have a bigger need of basic infrastructure and services than developed communities. Western development plans operate on the premise that the basic infrastructure and services for development are already in place when implementing their programs. This leads to failure because the programs have no solid foundation on which to build. Western development plans have to be adapted and tailored to fit the needs of the particular community and to build upon local knowledge, skills and resources. Fox and Van Rooyen [32] state that positive developments in Africa are often offset by the realities of daily life for its vast, poor rural populations. Conflict, disease, corruption and environmental disasters such as floods and droughts confirm this statement.

Fox and Van Rooyen [32] list the following socioeconomic variables hindering sustainable community development:

- A high dependence on agriculture at the subsistence level

- Significant disparities between rich and poor

- An unequal distribution of resources

- High unemployment and poverty rates

- Feudal and $\backslash$ or collective tenure arrangements 


\section{Challenges Specific to Rural South Africa}

According to South African Government Information [33] the challenges in rural areas in South Africa include an unsustainable use of natural resources, inadequate access to socio-economic and cultural infrastructure and services, a lack of access to water fr both households and agricultural developments, a low literacy rate and skills levels, migratory labor practices, a decay of the social fabric, and an abundance of unexploited opportunities in many economic sectors.

Fox and Van Rooyen [32] reason that "Africa's current rural development state is characterized by undercapitalization and lack of infrastructure". The rural economy mostly relies on agriculture as a primary form of industry, which is a risky endeavor as crops have been known to fail placing rural residents in dire financial straits. Infrastructure, such as roads to deliver goods, are poorly maintained and in some areas do not exist. Natural resources are also often utilized and managed unsustainably, with an over-exploitation of non-renewable resources and severe environmental degradation.

According to Fox and Van Rooyen [32] development projects have, traditionally, tended to be unsuccessful due to inadequate participation from local residents and a lack in capacity to implement them. To further exacerbate the problem policies regarding sustainable community development are often vague, broad and complex.

Due to the legacy of past policies, such as the former homelands system, rural South Africa has high-density population areas and dislocated settlement where residents live in abject poverty. The past injustices impede efforts of the rural people to maintain intact families and ensure a livelihood for themselves. Rural areas in South Africa have been experiencing economic and social decay over the past decades due to urban migration. Layard, Davoudi \& Batty [34] reason that this has in turn reduced the provision of services, facilities and employment opportunities in rural areas. Rural areas are also plagued with a lack of education and skills [32] which makes the challenge of finding adequate employment even harder.

Furthermore the ISRDS [20] states that HIV/AIDS poses and extensive challenge to rural development in South Africa because it impacts on a range of developmental factors. Rural areas are generally less equipped with resources to address this challenge, increasing the vulnerability of households.

\section{Conclusion}

After examining the various definitions of sustainable communities offered it is concluded that a sustainable community is one in which the residents meet their needs while making effective use of natural resources, enhancing the environment, achieving social cohesion and strengthening their economic prosperity in such a manner that the needs of future generations will be met. The crucial role of local authorities in achieving such settlements was also highlighted.
Through the scrutinization of the Venn-diagram it was deduced that sustainability within a community cannot be reached without first addressing all three spheres of sustainability and taking special cognizance of their inter-linkages.

While urban and rural communities may differ in many aspects they still share common challenges in achieving sustainable communities. It would appear as if rural communities are at more of a disadvantage than their urban counterparts and that rural areas in South Africa face problems that are uniquely their own. If all proposed solutions and strategies are not aimed at addressing the distinctive challenges of rural South Africa then they will continue to fail.

Acknowledgements

This research was made possible by the financial contribution of the NRF (National Research Foundation) South Africa. Any opinion, findings and conclusions or recommendations expressed in this material are those on the author(s) and therefor the NRF does not accept any liability I regard thereto.

\section{References}

[1] A. Tosten, I. Tvedten, and M. Vaa. Associational life in African cities - popular responses to the urban crisis. Stockholm: Elanders Gotab. 2001.

[2] J.

Collins.

Urbanisation http://www.bcb.uwc.ac.za/envfacts/facts/urbanisation.htm. 2001.

[3] United Nations. South Africa: Demographic profile 1950-2025. http://esa.un.org. 2012.

[4] E. Van Buren, H. Van Bohemen, L. Itard, and H. Visscher. Sustainable urban environments: an ecosystems approach. London: Springer. 2012.

[5] J.A. Elliot. An introduction to sustainable development: Fourth Edition. London: Routledge. 2013.

[6] P.P. Rogers, K.F. Jala, and J.A. Boyd. An Introduction to Sustainable Development. London: Earthscan. 2008.

[7] K.E. Portney. Taking sustainable cities seriously: economic development, the environment, and quality of life in American cities. Massachusetts: Massachusetts Institute of Technology. 2003.

[8] United Nations. Agenda 21. 1992.

[9] J. Ravetz. City Region 2020 - Integrated planning for a sustainable environment. Glasglow: Bell \& Bain Ltd. 2000.

[10] D. Collard, D.W. Pearce, and D. Ulph. Economics, Growth and Sustainable Environment. London: MacMillan. 1998.

[11] J.C. Bridger, and A.E.Luloff. Towards an interactional approach to sustainable community development. Journal of Rural Studies, vol 15, pp. 377-387, 1999.

[12] M. Roseland. Sustainable community development: integrating environmental, economic and social objectives. Progress in Planning, vol5, 99. 73-132, 2000. 
[13] M. Mohan, and E. Lutz. World Bank Environment Working Paper 42. Washington: World Bank. 1991.

[14] R. Goodland and H. Daly. Environmental Sustainability; Universal and Non-negotiable. Ecological Applications, vol6, 4. 1996.

[15] United Nations. Human Development Report. New York: Hoechstetter Printing Co. 2005.

[16] World Bank Inclusive Green Growth: The Pathway to Sustainable Development. Washington: International Bank fr Reconstruction and Development. 2012.

[17] B. Dalal-Clayton. and S. Bass. Sustainable development strategies: a resource book. London: Earthscan Publications Ltd. 2002.

[18] South Africa. Department of Land Affairs. Rural Development Framework. 1997.

[19] N. Gallent, M. Juntii, S. Kidd, and D. Shaw. Introduction to rural planning. New York: Routledge. 2008.

[20] South African Government. The Integrated Sustainable Rural Development Strategy. 2000.

[21] United Nations. Rural Development Commission on Sustainable Development, Decisions by Topic: Rural Development. 2009.

[22] United Nations. Trends in Sustainable Development: AGriculture, rural development, land desertification and drought. New York: Hoechstetter Printing Co. 2008.

[23] M.C. Behera. Globalising rural development - competing paradigms and emerging realities. London: Sage Publications Ltd. 2006.
[24] World Bank. Agriculture and Rural Development. http://web.worldbank.org. 2013.

[25] D. Gangopadyay, A.K. Muhhopadhyay, and P. Singh. Rural Development: A strategy for poverty alleviation India. http://www.nistads.res.in. 2008.

[26] C. Ling, K. Hanna, and A. Dale. A Template for Integrated Community Sustainability Planning. Environmental Management, vol 44, no 2, August, 2009.

[27] South African Cities Network. State of the cities report 2006. 2006.

[28] M.K. Smith. Sustainable Communities and Neighborhoods: Theory, Policy and Practice. http://www.infed.org. 2006.

[29] S. Campbell. Green cities, growing cities, just cities? Journal of the American Planning Association. 1996.

[30] M. Monto, L.S. Ganesh, and Varghese. Sustainability and Human Settlements. London: Sage Publications. 2005.

[31] T. Binns, and E. Nel. Beyond the development impasse: the role of local economic development and community self-reliance in rural South Africa. The journal of modern African studies, vol 37, no 3, 1999.

[32] W. Fox, and E. Van Rooyen. The Quest for Sustainable Development. Cape Town: Juta \& Co Ltd. 2004.

[33] South African Government Information. Rural development and land reform. http://www.info.gov.za. 2013.

[34] A. Layard, S. Davoudi, And S. Batty. Planning for a Sustainable Future. New York: Spoon Press. 2001. 